Article

\title{
Future Runoff Analysis in the Mekong River Basin under a Climate Change Scenario Using Deep Learning
}

\author{
Daeeop Lee ${ }^{1} \mathbb{D}$, Giha Lee ${ }^{2, *}$, Seongwon Kim ${ }^{1}$ and Sungho Jung ${ }^{2}$ \\ 1 Emergency Management Institute, Kyungpook National University, Sangju 37224, Korea; \\ hydroeop@gmail.com (D.L.); oper109@naver.com (S.K.) \\ 2 Department of Construction and Disaster Prevention Engineering, Kyungpook National University, \\ Sangju 37224, Korea; wjdtjdgh1547@gmail.com \\ * Correspondence: leegiha@knu.ac.kr; Tel.: +82-054-530-1259
}

Received: 20 April 2020; Accepted: 27 May 2020; Published: 29 May 2020

\begin{abstract}
In establishing adequate climate change policies regarding water resource development and management, the most essential step is performing a rainfall-runoff analysis. To this end, although several physical models have been developed and tested in many studies, they require a complex grid-based parameterization that uses climate, topography, land-use, and geology data to simulate spatiotemporal runoff. Furthermore, physical rainfall-runoff models also suffer from uncertainty originating from insufficient data quality and quantity, unreliable parameters, and imperfect model structures. As an alternative, this study proposes a rainfall-runoff analysis system for the Kratie station on the Mekong River mainstream using the long short-term memory (LSTM) model, a data-based black-box method. Future runoff variations were simulated by applying a climate change scenario. To assess the applicability of the LSTM model, its result was compared with a runoff analysis using the Soil and Water Assessment Tool (SWAT) model. The following steps (dataset periods in parentheses) were carried out within the SWAT approach: parameter correction (2000-2005), verification (2006-2007), and prediction (2008-2100), while the LSTM model went through the process of training (1980-2005), verification (2006-2007), and prediction (2008-2100). Globally available data were fed into the algorithms, with the exception of the observed discharge and temperature data, which could not be acquired. The bias-corrected Representative Concentration Pathways (RCPs) 4.5 and 8.5 climate change scenarios were used to predict future runoff. When the reproducibility at the Kratie station for the verification period of the two models (2006-2007) was evaluated, the SWAT model showed a Nash-Sutcliffe efficiency (NSE) value of 0.84, while the LSTM model showed a higher accuracy, NSE $=0.99$. The trend analysis result of the runoff prediction for the Kratie station over the 2008-2100 period did not show a statistically significant trend for neither scenario nor model. However, both models found that the annual mean flow rate in the RCP 8.5 scenario showed greater variability than in the RCP 4.5 scenario. These findings confirm that the LSTM runoff prediction presents a higher reproducibility than that of the SWAT model in simulating runoff variation according to time-series changes. Therefore, the LSTM model, which derives relatively accurate results with a small amount of data, is an effective approach to large-scale hydrologic modeling when only runoff time-series are available.
\end{abstract}

Keywords: deep learning; LSTM; SWAT; climate change scenario; Mekong River

\section{Introduction}

The Mekong River is an international river shared by six countries: China, Myanmar, Laos, Thailand, Cambodia, and Vietnam. It has a length of $4800 \mathrm{~km}$, a total basin area of 795,000 km², and 
abundant resources that are exploited for economic growth. However, various problems arise due to differences in the surrounding countries' development strategies, overall economic development, and positions regarding environmental issues [1]. In particular, conflict is intensifying due to the indiscriminate construction of dams to meet the recent explosive growth in hydropower demand, a consequence of regional economic growth.

Furthermore, due to the local economic structures being dependent on primary industries (e.g., agriculture, fishing, and forestry), although the sensitivity to climate change and exposure to extreme weather events are high, the budgets and response policies for preventing natural disasters are highly limited. Therefore, predicting future water resource variability due to long-term and short-term variations in precipitation and establishing response policies is a key issue in terms of reducing socio-economic damage and securing the safety of people [2]. In order to solve this problem and promote efficient basin development, a rainfall-runoff analysis must be carried out incorporating the effects of climate change. However, basic data pertaining to the Mekong River basin is insufficient and unreliable, which leads to a high uncertainty in analysis results.

According to the study of a research team at the University of Copenhagen based on more than 15,000 papers on climate in 197 countries, about $80 \%$ of the data related to climate change were published for developed countries [3]. Furthermore, these studies were also mostly targeted at rich countries, which are the least vulnerable to climate change while emitting the largest amounts of pollutants. Meanwhile, although more vulnerable to climate change, underdeveloped countries are not benefiting from related research [4]. This shows that there is an imbalance in knowledge about climate change between the countries that need and those that create the knowledge. This is an issue that needs to be resolved given its qualitative influence on each country's policy decisions related to preventing damage and adapting to climate change. However, there is concern that research bias is deepening over time due to limitations in infrastructure, the demand and financial support for related research, and the accuracy and accessibility of basic data. This bias is likely to widen the gap in response capabilities between underdeveloped and developed countries [5].

The Mekong River basin is one of the regions affected by an imbalance in knowledge related to climate change, and research efforts are not sufficient relative to the necessity. Most previous studies have simulated runoff changes based on the SRES (Special Report on Emission Scenario) and some on the RCP (Representative Concentration Pathways) scenarios for all or individual local basins of the Mekong River. The methods applied to predict future runoff include the SWAT (Soil and Water Assessment Tool) model [6,7], IQQM (Integrated Water Quantity and Quality Simulation Model) [7], SLURP (Semi-distributed Land Use-based Runoff Processes v.12.7) model [8], and VMod model [9,10]. As in these previous studies, the prediction of runoff using conceptual and physical models generally includes determining or estimating parameters. These parameters are mostly related to meteorological, topographic, and geological characteristics. When applying the models to regions with a low reliability of basic data, the parameters become physically-unreliable or spatiotemporally-insufficient, impacting the accuracy of the results.

As an alternative to existing runoff models, one can use a data-driven black-box hydrological model for which supervised training is performed for long-term input and output data and excluding any physical knowledge related to hydraulics and hydrology. Such a model has been recently developed because it has become possible to collect high-quality hydrological data based on the theory of artificial neural networks and deep learning open-source libraries have been released. For example, Tran and Song [11] and Jung et al. [12] used the LSTM (long short-term memory) technique proposed by Hochreiter and Schmidhuber [13] for hydrological time-series prediction. This model has been demonstrated to be capable of predicting more accurate hydrological time-series data by solving the long-term dependency problem of the recurrent neural network (RNN) model [2]. These studies show relatively high accuracy in the simple simulation of time-series changes in runoff, although they should be applied in more diverse conditions, such as including large watersheds and using complex learning data. 
In this study, a runoff analysis system using a data-based black-box hydrological model is proposed to predict future runoff for the Kratie water level observatory, one of the main stations along the Mekong River mainstream. The results are then used as basic data to analyze the water resources and evaluate the hydraulic and hydrological variations in downstream basins of the Mekong River, such as the Tonle Sap Lake in Cambodia and the Mekong Delta region in Vietnam. In addition, the applicability of the LSTM model is examined by comparing its results with those of the existing physical-based models. Since it is difficult to acquire local information, we used globally available data for model building and implemented a bias correction for the climate change scenarios. To this purpose, the observation data were rebuilt by dividing the upstream basin-including the Kratie water level observatory-into sub-basins. The constructed observation and climate change scenario datasets were used to perform a rainfall-runoff analysis based on both the SWAT model and the deep learning LSTM algorithm. Next, the applicability of the LSTM model is assessed by comparing the predicted variations in future runoff derived from both methods. Section 2 describes the theoretical background of the SWAT model, LSTM model, and climate change scenario for runoff analysis. Section 3 offers details about the study basin and the runoff analysis system. The runoff analysis results of each model are present in Section 4, while Section 5 summarizes and discusses the results of this study.

\section{Theoretical Background}

\subsection{Soil and Water Assessment Tool (SWAT)}

The Mekong River Commission (MRC) is now operating a decision support framework (DSF) for the utilization of water resources and prevention of water disasters in the Mekong River and a hydrological analysis system based on the SWAT model as the hydrological analysis toolbox of the DSF. The SWAT model is a semi-distributed long-term rainfall-runoff model developed by the Agricultural Research Service of the United States Department of Agriculture (USDA). It can predict not only runoff but also sediment and chemical pollutant transport in large complex basins with various types of soils and lands. The SWAT model uses the topographic and water system data on the Geographic Information System (GIS) to divide the target basin into sub-basins and the sub-basins into hydrologic response units (HRUs), which show the same land-use status and soil characteristics as the basin. In the SWAT model, the hydrological cycles are calculated using the following water balance equation:

$$
S W_{t}=S W_{O}+\sum_{i=1}^{t}\left(R_{\text {day }}-Q_{\text {surf }}-E_{a}-W_{\text {seep }}-Q_{g w}\right)
$$

where $S W_{t}$ is the final soil water content $(\mathrm{mm}), S W_{O}$ the initial soil water content per day $(\mathrm{mm}), t$ the time (day), $R_{\text {day }}$ the amount of precipitation per day $(\mathrm{mm}), Q_{\text {surf }}$ the amount of surface runoff per day $(\mathrm{mm}), E_{a}$ the amount of evapotranspiration per day $(\mathrm{mm}), W_{\text {seep }}$ the amount of water entering the vadose zone from the soil profile per day $(\mathrm{mm})$, and $Q_{g w}$ is the amount of return flow per day $(\mathrm{mm})$.

The SWAT-CUP (Calibration and Uncertainty Program) developed by Eawag, a Swiss federation research institute, can be used as an auxiliary program for the SWAT model parameter correction during the automatic calibration of parameters. A suitable algorithm can be selected among the following five: SUFI-2 (sequential uncertainty fitting-version 2), GLUE (generalized likelihood uncertainty estimation), ParaSol (parameter solution), MCMC (Monte Carlo Markov chain), and PSO (particle swarm optimization). In this study, the parameters were optimized using the SUFI-2 algorithm, which was deemed appropriate for handling the uncertainty typical for a SWAT model [14] and reliable after being applied to the basins of various countries, including China [15], Ethiopia [16], and Laos [17].

\subsection{Long Short-Term Memory (LSTM)}

This deep learning algorithm has been used in various fields, including remote sensing, topography, geology, as well as hydraulics and hydrology since late 2010, when various open-source software 
libraries related to deep learning were developed. In the present study, we constructed a deep neural network to simulate the runoff of the Mekong River basin using TensorFlow, developed by Google.

The LSTM model applied in this study was first proposed in 1997 by Hochreiter and Schmidhuber [13] as a modified version of the RNN model, one of the artificial neural network algorithms used mainly for analyzing time-related continuous data when continuous observation values are correlated. The most important characteristic of RNN is that it saves the state at a specific time and changes the state according to the input and output at each moment in time. Although there are many different types of RNN, the basic principle is as follows: the status at time $t\left(h_{t}\right)$ is determined by the previous state $\left(h_{t-1}\right)$ and the current input $\left(x_{t}\right)$. Since the output $\left(y_{t}\right)$ is determined by the state $\left(h_{t}\right)$, it reflects the sequential dependency of the data.

To train data with a long temporal length in the basic RNN, it takes plenty of training time and a deep RNN layer. When a layer is built, long-term patterns cannot be trained due to the vanishing gradient problem, common for general neural networks. Moreover, when the training time is long, the data changes slightly as it passes through the neural network. Consequently, the long-term dependency problem causes the memory that was initially input to disappear gradually, thus degrading the learning ability and making it impossible to use data from the past. To address this problem, when the weights are updated, the LSTM algorithm was designed to determine whether to keep remembering or forget previous information, distinguishing between the data to be stored and the ones to ignore.

To update the state $\left(h_{t}\right)$ at a specific time, LSTM introduces the concept of long-term memory (cell state, $C_{t}$ ) and determines whether or not to update the internal information using the input and the state until now, thus solving the long-term dependency problem [18]. When the sequential data is organized to some extent, the state information until now is forgotten and the newly entered data is used more. By contrast, if the new input data is not useful, the state until the previous step is remembered for more time and fewer updates are performed. Then, this state is finally stored in the cell. The computation process of LSTM can be summarized as follows.

First, the forget gate $\left(f_{t}\right)$ determines whether to accept the previous state $\left(h_{t-1}\right)$ and a new input value $\left(x_{t}\right)$ in the cell and maintain the information or to remove it according to the following equation:

$$
f_{t}=\sigma\left(W_{t}\left[h_{t-1}, x_{t}\right]\right)
$$

where $\sigma$ is the sigmoid function and $W_{t}$ is the weight of the forget gate.

Second, the input gate $\left(i_{t}\right)$ determines whether or not to save certain information in the cell, as in Equation (3). The input gate has two active function layers, a sigmoid and a tan $h$. The value to be updated using the sigmoid function and the vector value of the candidate cell $\left(\widetilde{C}_{t}\right)$ that can be added to the long-term memory in the tan $h$ layer are generated. Then, these two values are multiplied to update the data state, as follows:

$$
\begin{gathered}
i_{t}=\sigma\left(W_{i}\left[h_{t-1}, x_{t}\right]\right) \\
\widetilde{C}_{t}=\tanh \left(W_{c} \cdot\left[h_{t-1}, X_{t}\right]\right)
\end{gathered}
$$

where $W_{i}$ is the weight of the input gate and $W_{c}$ is the weight of the candidate cell.

Next, the past cell state $\left(C_{t-1}\right)$ and the candidate cell $\left(\widetilde{C}_{t}\right)$ are combined according to Equation (5) to update the current cell state $\left(C_{t}\right)$.

$$
C_{t}=f_{t} \cdot \widetilde{C}_{t-1}+i_{t} \cdot \widetilde{C}_{t}
$$

Third, the output gate $\left(O_{t}\right)$ determines which part of the cell state to output using the sigmoid function as in Equation (6). Finally, it updates the state of a specific time $\left(h_{t}\right)$ by multiplication with the tan $h$ of the active cell state $\left(C_{t}\right)$, as shown in Equation (7):

$$
\begin{gathered}
O_{t}=\sigma\left(W_{o} \cdot\left[h_{t-1}, X_{t}\right]\right) \\
h_{t}=O_{t} \cdot \tanh \left(C_{t}\right)
\end{gathered}
$$


where $W_{O}$ is the weight of the output gate.

The LSTM model determines selectively how many current states to memorize, how much to update, and what to update according to the previous and current states by introducing the cell concept. Thus, compared with the RNN, it can model correlations that are more complex and further along in time $[2,11]$.

\subsection{Climate Change Scenario}

The climate change scenario refers to the information regarding future climate (e.g., temperature, precipitation, humidity, and wind) calculated using a climate change prediction model in order to anticipate when, where, and how climate change will occur due to anthropogenic causes, such as greenhouse gases, aerosols, and land-use conditions. In 1988, the World Meteorological Organization (WMO) and UN Environment Programme (UNEP) established the Intergovernmental Panel on Climate Change (IPCC) to respond to climate change as an affiliated organization of the United Nations. The IPCC mainly collects and analyzes scientific evidence of climate change and develops and suggests various measures to respond to it, publishing evaluation reports once every five to six years [19]. The currently used RCP scenario was adopted as a new greenhouse gas scenario to replace the existing SRES in the climate change expert meeting held in September 2007 in The Netherlands and it uses four representative greenhouse gas concentrations $(2.6,4.5,6.0,8.5)$ as major consequences of human activity that affect the atmosphere.

The RCP regional climate change scenario applied in this study consists of about 50-km-resolution data from Hadley Centre Global Environmental Model version 3 Regional Atmosphere (HadGEM3-RA) pertaining to the East Asian region. The data is divided into a simulation of the past climate (1950-2005) and a climate change prediction until 2100. HadGEM3-RA is a regional climate model based on the atmosphere model of HadGEM3, an Earth system model of the Hadley Center of the British Weather Service. The East Asian regional scenario of HadGEM3-RA was created through the CODEX (Coordinated Regional Climate Downscaling Experiment), an international project for regional climate downscaling projects. For the input data for HadGEM3-RA, global climate change scenarios at a 135-km grid scale are employed; detailed regional climate change scenarios have been known to reflect well the complex topographical effects that cannot be represented by the global climate model [20]. To create the climate change data for the Mekong River basin, an approximately $50 \mathrm{~km}$-resolution curvilinear grid in the East Asian regional scenario of HadGEM3-RA was converted into a $0.5^{\circ}$ rectilinear grid. The RCP 4.5 and 8.5 scenarios, generally used by climate-change-related previous studies, were chosen out of a total of four representative scenarios, thereby building daily scenario data consisting of $\mathrm{Pr}$ (precipitation), Tasmax (maximum temperature) and Tasmin (minimum temperature). The RCP 4.5 is to a scenario in which greenhouse gas emission policy is realized, and RCP 8.5 is a scenario in which greenhouse gas is emitted in the current trend. The two scenarios are selected as general comparison scenarios in connection with climate change response policies.

However, the climate change scenario contains a certain amount of uncertainty due to the following limitations: incomplete physical understanding of various natural conditions, the selection of future virtual scenarios, and computational performance [21-25]. Thus, a bias-correction process using the observation data is needed to minimize the uncertainty in the climate change scenario. This study implements the correction process of future (2006-2100) rainfall and temperature data by calculating the correction coefficient and cumulative probability distribution through a comparison with the observation and historical climate change data from the past (1951-2005). When performing the bias correction, globally available data were used for the rainfall. However, continuous daily temperature data could not be acquired. As a result, the monthly mean temperature between 2005 and 2015 was utilized instead. Two of the most widely used bias-correction techniques, the change factor and quantile mapping methods, were used to perform the bias correction. Each of the techniques is described below. 


\subsubsection{The Change Factor Method}

The change factor method is a well-known statistical approach that determines means based on the observation means obtained in a certain period selected from the past is moved or re-scaled. The change factor method calculates the calibration factor using the annual or monthly mean in the bias-correction period as follows. The factor is then applied to the future period.

$$
T_{\mathrm{GCM} \cdot f u t}^{\prime}=\mathrm{T}_{\text {mean }}+\left(\overline{\mathrm{T}}_{\mathrm{GCM} \cdot \mathrm{fut}}-\overline{\mathrm{T}}_{\mathrm{GCM} \cdot \mathrm{his}}\right)
$$

where $T_{\mathrm{GCM} \text {.fut }}^{\prime}$ is the corrected future temperature $\left({ }^{\circ} \mathrm{C}\right), \mathrm{T}_{\text {mean }}$ the mean past observation temperature, $\overline{\mathrm{T}}_{\mathrm{GCM}}$.fut the future scenario mean temperature $\left({ }^{\circ} \mathrm{C}\right)$, and $\overline{\mathrm{T}}_{\mathrm{GCM}}$.his the past scenario mean temperature $\left({ }^{\circ} \mathrm{C}\right)$.

\subsubsection{Quantile Mapping}

The scaled results from the climate change model have a certain level of bias compared with the actual measurements. To correct this bias, one of the most widely used methods is quantile mapping, which maps the probabilistic distribution of the scenario simulation values-where the bias occurs-to the probabilistic distribution of observation values. As shown by Equation (9), this is accomplished using the cumulative probabilistic distribution of the observation and scenario simulation values in the past, when they exist simultaneously.

$$
Z_{i}=F_{O i}^{-1}\left(F_{S i}\left(\hat{Y}_{i}\right)\right)
$$

where $\hat{Y}_{i}$ is the simulation value prior to calibration, $Z_{i}$ the simulation value after calibration, $F_{S i}$ the cumulative probabilistic distribution of existing simulation values, and $F_{O i}$ he cumulative probabilistic distribution of observation values.

The most basic methods were used for the bias correction methods applied in this study due to limitations in the study (lack of temperature data, application of the rainfall-runoff model, etc.). Therefore, it is necessary to consider the application of various techniques and ensemble scenarios, such as previous studies related to climate change scenarios [26-29] through additional studies in the future.

\section{Modeling Processes}

\subsection{Target Basin}

As shown in Figure 1a, the Mekong River is an international river shared by six nations: China, Myanmar, Laos, Thailand, Cambodia, and Vietnam. Its length is $4800 \mathrm{~km}$ and it drains an area of $795,000 \mathrm{~km}^{2}$. Table 1 presents the information of the basin area and water flow contribution by country share. The region has a high economic development potential, having contributed to the growth of industries related to agriculture, fishery, and hydraulic power due to the large quantity of water and natural resources, such as forest products and minerals.

However, various problems occur in the development of the basin as a result of it being shared by several nations. In particular, conflicts due to dam construction have aggravated. As shown in Figure $1 b$, China has now completed and is operating six dams along the upstream of the Mekong River as of 2013. Consequently, water shortages have occurred downstream of the Mekong River, while the sudden discharge of water has caused other water-related problems, such as floods. It is very important to consider the effect of upstream dams on the downstream basins of the Mekong River; however, China does not offer access to the basic hydrological data. Accordingly, the MRC applies the Mekong River basic development scenario for the runoff analysis of the downstream basins. However, the MRC also does not grant access to details about the calculation methods and criteria of the related 
scenarios. Thus, it is difficult for general researchers who are not related to the institution to apply the scenarios.

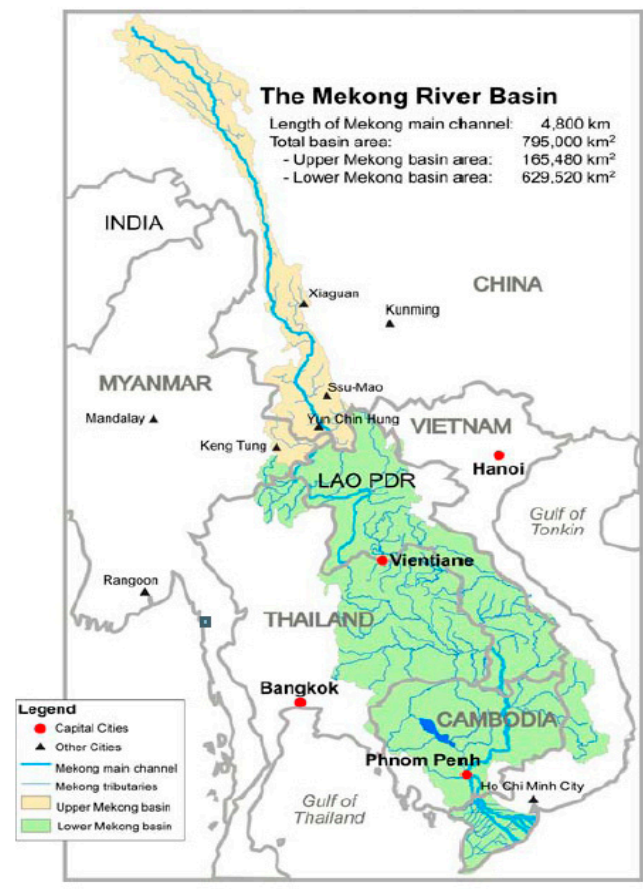

(a)

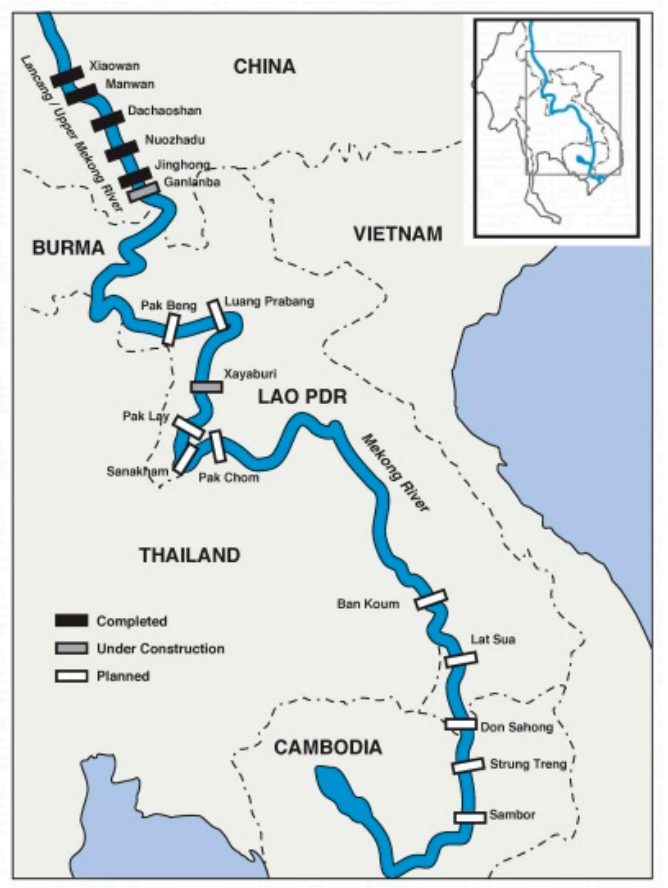

(b)

Figure 1. The Mekong River basin and its characteristics. (a) Mekong River basin [30]; (b) Mekong mainstream dams [31].

Table 1. Summary of country shares of the Mekong Basin territory and water flows [31].

\begin{tabular}{|c|c|c|c|c|c|c|c|}
\hline Information & China & Myanmar & Lao PDR & Thailand & Cambodia & Vietnam & Total \\
\hline Area in Basin $\left(\mathrm{km}^{2}\right)$ & 165,000 & 24,000 & 202,000 & 184,000 & 155,000 & 65,000 & 795,000 \\
\hline $\begin{array}{l}\text { Catchment as \% of } \\
\text { Mekong River Basin }\end{array}$ & 21 & 3 & 25 & 23 & 20 & 8 & 100 \\
\hline $\begin{array}{c}\text { Flow as } \% \text { of Mekong } \\
\text { River Basin }\end{array}$ & 16 & 2 & 35 & 18 & 18 & 11 & 100 \\
\hline
\end{tabular}

When performing the rainfall-runoff simulation using the SWAT model, a hydrological analysis of the downstream basins can be performed by applying the inflow discharge from the station where the water level data is constructed to the upstream boundary condition. To reduce this uncertainty, this study divided the target basins into upstream and downstream before and after the Chiang Saen observatory, respectively, which is the most upstream station that could acquire the water level data, as shown in Figure 2 in the runoff analysis process using the SWAT model. Here, the runoff data simulated at the Chiang Saen station (basin area: 184,500 $\mathrm{km}^{2}$ and $18 \%$ of the annual mean flow rate) are utilized as the inflow data for runoff simulations for the Kratie station downstream of the Mekong River (basin area: $437,200 \mathrm{~km}^{2}$ and $88 \%$ of the annual mean flow rate). Furthermore, the basins in the upstream were divided into four sub-basins and 26 HRUs, while the basins in the downstream (basin area: 556,100 $\mathrm{km}^{2}$ ), including the Kratie station, were divided into 24 sub-basins and 191 HRUs, thereby preparing the basic data of the 28 sub-basins. The present study utilized the data up to the 23rd sub-basin (Kratie station). 


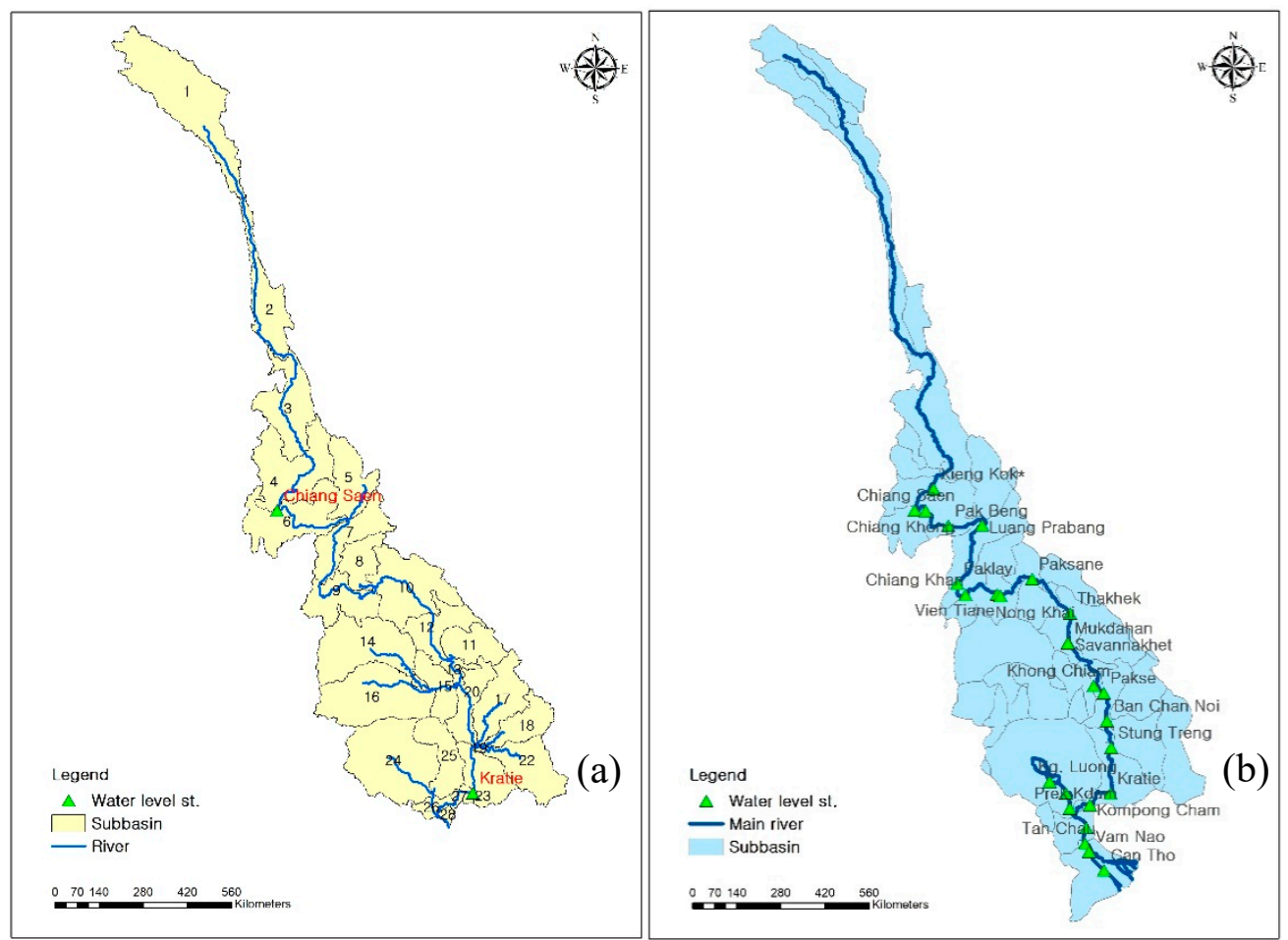

Figure 2. Modeling domain. (a) Division of basins in the study area; (b) main water level stations of the Mekong River.

\subsection{The SWAT Model}

The collection and processing procedure of the following basic data (hydrometeorology, topography, land use, soil, etc.) was performed for rainfall-runoff simulations using the SWAT model. For the digital elevation model, the hydrological data and maps based on Shuttle Elevation Derivatives at multiple Scales (HydroSHEDS) were provided by the U.S. Geological Survey (USGS). For the land-cover map, the Moderate Resolution Imaging Spectroradiometer (MODIS) Land Cover was provided by the Global Land Cover Facility (GLCF), while the general data for the soil map was supplied by the Food and Agriculture Organization of the United Nations (FAO). It should be noted that the spatial resolution differs by dataset. Hence, this study reconstructed the input data in the SWAT model based on a 30-arc-second (around $1 \mathrm{~km}$ ) resolution, equivalent to that of the MODIS Land Cover data. Concerning the observed rainfalls, although many observatories exist in the Mekong River basin, their observation periods were different from one another and some observatories had long-term non-measured periods, which caused the reliability of the ground observation data to be relatively low. This problem can be confirmed by a comparison conducted by Wang et al. [32] between the station rainfall data in the Mekong River basin and runoff analysis results using data from the Tropic Rainfall Measurement Mission (TRMM). This study collected the daily rainfalls from 1951 to 2007 from the Asian Precipitation Highly Resolved Observational Data Integration Towards Evaluation of Water Resources (APHRODITE), provided in a grid-based form of the rainfall field. After calibration using the station rainfall data in Asian regions, the daily rainfalls were subsequently converted to the area precipitation of 23 sub-basins applying the converted data were utilized. As mentioned above, continuous daily meteorological data (maximum and minimum temperature) could not be acquired. Thus, we considered instead the monthly mean data between 2005 and 2015 in 12 major cities.

The simulation period to derive the optimal parameters and verify the model was 2000 to 2007, including one year for the warm-up period. The parameter correction was performed using observation data, such as rainfalls, weather, and flow rate, between 2001 and 2005 for two stations, Chiang Saen and Kratie, while verifications were conducted for the 2006-2007 period using the calibrated parameters. 
Next, the future runoff variations were simulated for the 2008-2100 interval using the bias-corrected future climate change RCP 4.5 and 8.5 scenarios using the parameters produced by calibration and verification. Eleven main parameters previously used by Shrestha et al. [17] and Lee et al. [33] and three parameters in relation to base flow to indirectly account for the effect of the upstream dams at the Chiang Saen station were added and applied. Table 2 shows the optimal parameters selected for the Chiang Saen and Kratie stations.

Table 2. The optimal parameters estimated by Soil and Water Assessment Tool-Calibration and Uncertainty Program (SWAT-CUP).

\begin{tabular}{|c|c|c|c|c|c|}
\hline \multirow{2}{*}{ Parameter } & \multirow{2}{*}{ Description (unit) } & \multicolumn{2}{|c|}{ Range } & \multicolumn{2}{|c|}{ Fitted Value } \\
\hline & & Min & Max & Chiang Saen & Kratie \\
\hline ALPHA_BF.gw & Base flow alpha factor (1/days) & 0 & 1 & 0.006 & 0.024 \\
\hline RCHRG_DP.gw & $\begin{array}{l}\text { Deep aquifer percolation } \\
\text { fraction }(-)\end{array}$ & 0 & 1 & 0.030 & 0.917 \\
\hline CN2.mgt & Curve number (-) & 35 & 98 & 38.661 & 58.188 \\
\hline $\mathrm{CH} \_\mathrm{K} 2$. rte & $\begin{array}{l}\text { Channel effective hydraulic } \\
\text { conductivity ( } \mathrm{mm} / \mathrm{hr} \text {.) }\end{array}$ & -0.01 & 500 & 8.496 & 0.754 \\
\hline SOL_AWC (..).sol & $\begin{array}{l}\text { Available water capacity } \\
(\mathrm{mm} / \mathrm{mm})\end{array}$ & 0 & 1 & 0.349 & 0.053 \\
\hline CH_N2.rte & $\begin{array}{l}\text { Manning's n-value for main } \\
\text { channel (-) }\end{array}$ & -0.01 & 0.3 & 0.105 & 0.225 \\
\hline SURLAG.bsn & Surface runoff lag (days) & 1 & 24 & 19.290 & 0.985 \\
\hline ESCO.hru & $\begin{array}{l}\text { Soil evaporation compensation } \\
\text { factor }(-)\end{array}$ & 0 & 1 & 0.069 & 0.743 \\
\hline SOL_K (..).sol & $\begin{array}{l}\text { Saturated hydraulic } \\
\text { conductivity }(\mathrm{mm} / \mathrm{h})\end{array}$ & 0 & 2000 & 493.078 & 136.597 \\
\hline GW_DELAY.gw & Groundwater delay time (days) & 0 & 500 & 479.475 & 241.528 \\
\hline CANMX.hru & Canopy storage $(\mathrm{mm})$ & 0 & 100 & 61.959 & 46.021 \\
\hline GWQMN.gw & $\begin{array}{l}\text { Threshold depth of water in the } \\
\text { shallow aquifer required for } \\
\text { flow to occur (mm) }\end{array}$ & 0 & 500 & 41.949 & 624.521 \\
\hline GW_REVAP.gw & Groundwater revap coefficient & 0.02 & 0.2 & 0.058 & 0.159 \\
\hline REVAPMN.gw & $\begin{array}{l}\text { Threshold depth of water in the } \\
\text { shallow aquifer for revap or } \\
\text { percolation to the deep aquifer } \\
\text { to occur (mm) }\end{array}$ & 0 & 500 & 0.169 & 126.214 \\
\hline
\end{tabular}

\subsection{The LSTM Model}

The quantitative and qualitative reliability of the learning data is very important for the TensorFlow learning and prediction within the LSTM model. The data of the Kratie water level observatory, which was the main analysis station in this study, correspond to a relatively long period of time (2000 to 2014) compared to the data from other stations along the mainstream of the Mekong River. Furthermore, the water level data from the Kratie station have been used and verified by various studies, which indicates a relatively higher reliability than the data from other stations. There are a number of ways to design the input and output lengths in the RNN-based LSTM model. Among them, the many-to-one method, which generates one output through the learning of many input data, has been occasionally utilized in hydrology. A typical example is predicting the water level in a downstream station using the time-series water level data from many stations along the upstream [2]. As shown in Figure 3, this study performed learning and prediction using the observation rainfalls to apply the climate change scenario, rainfalls in the bias-corrected future climate change scenario, and water level data from the Kratie station. The grid-type rainfall data were converted to the daily area rainfall in 28 sub-basins and applied, while the data for 23 out of 28 sub-basins in the upstream-including the Kratie station-were used in learning. A total of 24 datasets-the observation rainfalls in 23 basins and observation water levels at the Kratie station-were trained during the learning period (1980-2005), while the verification was done how the learning was well done in the verification period (2006-2007). In the next step, 
the water level at the Kratie station was predicted by using the climate change scenario rainfalls in 23 basins during the prediction period (2008-2100). At step $t$, the predicted water level at step $t-1$ was used to predict the water level at step $t+1$. The predicted water level was converted into a flow rate using the water level-flow rate relationship curve equation, and then compared with the results produced by the SWAT model. The reason for the use of the water level data in learning and prediction was because the water level-flow rate curve equation at the station provided by the MRC had not been constantly updated since 2004, thereby containing uncertainty and introducing distortion when training the neural network. Thus, this study predicted the Kratie water level using the LSTM model and converted it to a flow rate, thereby analyzing the simulation results.

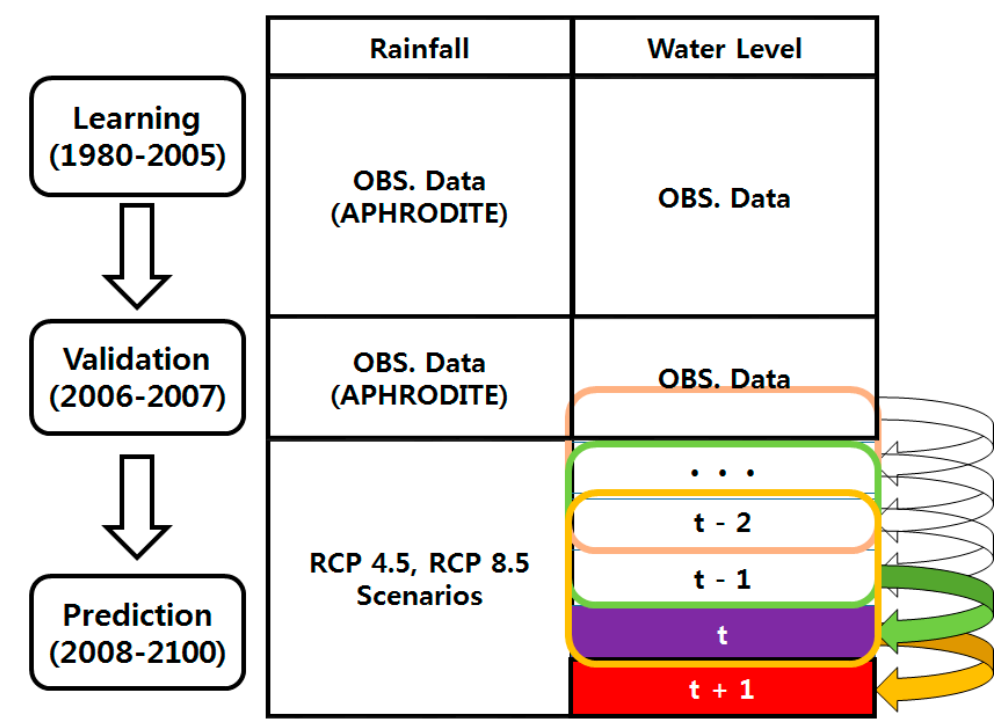

Figure 3. A conceptual diagram of the water level changes using the long short-term memory (LSTM) model.

For the parameters in the LSTM model, the learning rate was fixed to 0.01 through sensitivity analysis and the number of hidden layers was set to 48. In addition, the number of epochs was set to 1200 times for sufficient learning of the neural network. Finally, to consider the temporal continuity of the flood wave in the Mekong River, the sequence length was changed via seven cases: 1 day, 3 days, 6 days, 9 days, 12 days, 15 days, and 20 days to investigate the reproducibility of the prediction results according to the temporal change of the learning data. Here, the sequence length refers to the learning period for predicting the water level at $t+1$. For example, if the sequence length is 3 days, the water level at $t+1$ is predicted using the data between $t-2$ and $t$. For the activation function, the back-propagation algorithm using the sigmoid and tan $\mathrm{h}$ functions, which are most widely used in LSTM, were employed.

\subsection{Trend Analysis of the Climate Change Scenario}

The bias correction was conducted to minimize the uncertainty regarding rainfalls and the maximum and minimum temperatures using the observation data in the RCP 4.5 and 8.5 scenarios. The bias-corrected climate change scenario was utilized as data for the runoff analysis for a future period. To identify any trends, we conducted the Mann-Kendall (M-K) test, a non-parametric method [34,35] widely used in hydrologic time-series analysis [36]. In this study, after performing the Kendall test for each season independently, we conducted the seasonal $\mathrm{M}-\mathrm{K}$ test, which excludes seasonality, by calculating a weighted sum of each result, thereby deriving a single trend analysis result. In this way, we determined whether there was a trend by verifying the significance after calculating the correlation coefficient Kendall's Tau [37]. The hypothesis test for identifying a trend in the changes in rainfall by sub-basin was conducted assuming the significance level was 0.05 . The $p$-value derived through the 
seasonal M-K test is an index used to verify the significance or a correlation; a $p$-value smaller than the significance level indicates there is a trend.

Table 3 presents the summarized analysis results for the yearly rainfall trend determined by the seasonal M-K test for each basin and scenario. The results show that, in one out of a total of 23 basins in the 1951-2005 historical scenario, the increase in rainfall was a statistically significant trend. The analysis results revealed that, in the RCP 4.5 scenario of the future period (2006-2100), the increase in rainfall in four basins was statistically significant, while in the RCP 8.5 scenario, the increase in rainfall in six basins and decrease in rainfall in two basins were statistically significant. Table 4 presents the summarized trend analysis of the maximum and minimum temperatures for each basin and scenario. It can be observed that the increase in maximum and minimum temperatures in all 12 basins were statistically significant trends. Furthermore, the temperature rise was more significant in the RCP 8.5 scenario than in the RCP 4.5 scenario when referring to the Kendall's Tau values, while the increase in minimum temperature was relatively more significant than the increase in maximum temperature.

Table 3. The results of the Mann-Kendall trend test (precipitation).

\begin{tabular}{ccccccc}
\hline \multirow{2}{*}{ Basin } & \multicolumn{2}{c}{ Historical } & \multicolumn{2}{c}{ RCP 4.5} & \multicolumn{2}{c}{ RCP 8.5 } \\
\cline { 2 - 7 } & Tau & $p$-Value & Tau & $p$-Value & Tau & $p$-Value \\
\hline 1 & 0.170 & 0.066 & 0.171 & 0.014 & 0.144 & 0.038 \\
2 & 0.282 & 0.002 & 0.082 & 0.238 & 0.320 & $<0.0001$ \\
3 & 0.026 & 0.777 & -0.009 & 0.900 & 0.263 & $<0.0010$ \\
4 & -0.161 & 0.083 & 0.056 & 0.420 & 0.299 & $<0.0001$ \\
5 & -0.122 & 0.189 & 0.079 & 0.259 & 0.245 & $<0.0010$ \\
6 & -0.160 & 0.085 & 0.105 & 0.133 & 0.209 & 0.003 \\
7 & -0.095 & 0.306 & 0.136 & 0.051 & 0.078 & 0.265 \\
8 & -0.056 & 0.547 & 0.181 & 0.009 & 0.095 & 0.174 \\
9 & -0.044 & 0.637 & 0.131 & 0.061 & -0.014 & 0.845 \\
10 & 0.042 & 0.647 & 0.141 & 0.043 & -0.008 & 0.910 \\
11 & -0.028 & 0.766 & 0.007 & 0.921 & -0.225 & 0.001 \\
12 & -0.002 & 0.983 & 0.075 & 0.279 & -0.084 & 0.230 \\
13 & 0.021 & 0.822 & 0.023 & 0.741 & -0.141 & 0.043 \\
14 & -0.044 & 0.637 & 0.075 & 0.281 & -0.039 & 0.578 \\
15 & -0.005 & 0.959 & 0.075 & 0.284 & -0.111 & 0.110 \\
16 & -0.018 & 0.845 & -0.012 & 0.865 & -0.058 & 0.409 \\
17 & 0.096 & 0.299 & 0.049 & 0.477 & -0.045 & 0.518 \\
18 & 0.049 & 0.596 & 0.049 & 0.477 & -0.013 & 0.855 \\
19 & -0.056 & 0.547 & 0.130 & 0.063 & -0.010 & 0.890 \\
20 & 0.040 & 0.668 & 0.059 & 0.394 & -0.116 & 0.095 \\
21 & -0.061 & 0.509 & 0.096 & 0.170 & -0.027 & 0.702 \\
22 & -0.025 & 0.788 & -0.005 & 0.941 & -0.111 & 0.110 \\
23 & -0.041 & 0.658 & 0.149 & 0.033 & -0.006 & 0.936 \\
\hline & & & & & &
\end{tabular}

Table 4. The results of the Mann-Kendall trend test (temperature).

\begin{tabular}{ccccccccc}
\hline \multirow{2}{*}{ Basin } & \multicolumn{2}{c}{ RCP 4.5 (Min.) } & \multicolumn{2}{c}{ RCP 4.5 (Max.) } & \multicolumn{2}{c}{ RCP 8.5 (Min.) } & \multicolumn{2}{c}{ RCP 8.5 (Max.) } \\
\cline { 2 - 9 } & Tau & $\boldsymbol{p}$-Value & Tau & $\boldsymbol{p}$-Value & Tau & $\boldsymbol{p}$-Value & Tau & $p$-Value \\
\hline 1 & 0.7 & $<0.0001$ & 0.5 & $<0.0001$ & 0.8 & $<0.0001$ & 0.8 & $<0.0001$ \\
3 & 0.8 & $<0.0001$ & 0.6 & $<0.0001$ & 0.9 & $<0.0001$ & 0.7 & $<0.0001$ \\
6 & 0.7 & $<0.0001$ & 0.5 & $<0.0001$ & 0.9 & $<0.0001$ & 0.8 & $<0.0001$ \\
7 & 0.7 & $<0.0001$ & 0.5 & $<0.0001$ & 0.8 & $<0.0001$ & 0.8 & $<0.0001$ \\
9 & 0.6 & $<0.0001$ & 0.5 & $<0.0001$ & 0.8 & $<0.0001$ & 0.8 & $<0.0001$ \\
14 & 0.7 & $<0.0001$ & 0.5 & $<0.0001$ & 0.9 & $<0.0001$ & 0.8 & $<0.0001$ \\
15 & 0.7 & $<0.0001$ & 0.5 & $<0.0001$ & 0.9 & $<0.0001$ & 0.8 & $<0.0001$ \\
\hline
\end{tabular}


Table 4. Cont.

\begin{tabular}{ccccccccc}
\hline \multirow{2}{*}{ Basin } & \multicolumn{2}{c}{ RCP 4.5 (Min.) } & \multicolumn{2}{c}{ RCP 4.5 (Max.) } & \multicolumn{2}{c}{ RCP 8.5 (Min.) } & \multicolumn{2}{c}{ RCP 8.5 (Max.) } \\
\cline { 2 - 9 } & Tau & $\boldsymbol{p}$-Value & Tau & $\boldsymbol{p}$-Value & Tau & $\boldsymbol{p}$-Value & Tau & $\boldsymbol{p}$-Value \\
\hline 16 & 0.7 & $<0.0001$ & 0.5 & $<0.0001$ & 0.9 & $<0.0001$ & 0.8 & $<0.0001$ \\
20 & 0.7 & $<0.0001$ & 0.5 & $<0.0001$ & 0.9 & $<0.0001$ & 0.8 & $<0.0001$ \\
22 & 0.8 & $<0.0001$ & 0.6 & $<0.0001$ & 0.9 & $<0.0001$ & 0.8 & $<0.0001$ \\
24 & 0.7 & $<0.0001$ & 0.5 & $<0.0001$ & 0.9 & $<0.0001$ & 0.8 & $<0.0001$ \\
26 & 0.7 & $<0.0001$ & 0.5 & $<0.0001$ & 0.9 & $<0.0001$ & 0.8 & $<0.0001$ \\
\hline
\end{tabular}

\section{Runoff Analysis Result}

\subsection{SWAT Runoff Analysis Result}

As previously mentioned, the simulation period to derive the optimal parameters and verify the model was comprised between 2000 and 2007, including one year for the warm-up period. The parameter optimization for the 2000-2005 period was conducted using observations and globally available data. The optimal parameters in Table 2 were derived, and the verifications were performed for the 2006-2007 period. The results of the rainfall-runoff simulation for each station in the corresponding period are shown in Figure 4. The following Nash-Sutcliffe efficiency (NSE) was calculated to quantify the accuracy of the simulation results.

$$
N S E=1-\frac{\sum_{t=1}^{N}\left(O_{t}-P_{t}\right)^{2}}{\sum_{t=1}^{N}\left(O_{t}-\bar{O}\right)^{2}}
$$

where $N$ is the number of data points, $O_{t}$ and $P_{t}$ are the observed and simulated discharge at time $t$, and $\bar{O}$ is the mean value of the observed discharge.

Figure 4 a shows the runoff analysis results in the Chiang Saen station, in which the NSE in the calibration period (2001-2005) was 0.82 and in the verification period (2006-2007) was 0.59, indicating that the reproducibility in the verification period was reduced compared to that in the calibration period. As the shape of the low water level section in the runoff analysis result at the Chiang Saen station was a relatively straight line, it confirmed the overall flow rate increase due to the base flow rate. This is also in agreement with the most sensitive parameter, ALPHA_BF.gw, involved with the base runoff in the parameter sensitivity analysis results. Figure 4 b shows the runoff analysis result in the Kratie station. The NSE in the calibration period (2001-2005) was 0.85 and in the verification period (2006-2007) 0.84, which indicates that both the parameter calibration and verification periods showed a relatively high reproducibility. The parameter sensitivity analysis results at the Kratie station also suggest that CH_N2.rte, one of the parameters that represents the physical characteristics of rivers, was the most sensitive parameter.

The above result implies that its accuracy may be affected by uncertainty added during the selection and calibration of parameters in addition to the uncertainty in the basic data at the time of the runoff analysis using physical models. The runoff analysis results can vary due to a number of conditions, such as the selection of parameters applied to the runoff analysis, selection of mapping for parameter calibration, observation stations for parameter calibration, and the number of target basins. The above results confirmed that additional uncertainties may occur if basic data is difficult to acquire and the reliability of the developed data is relatively low, as is the case in the target area of this study. 


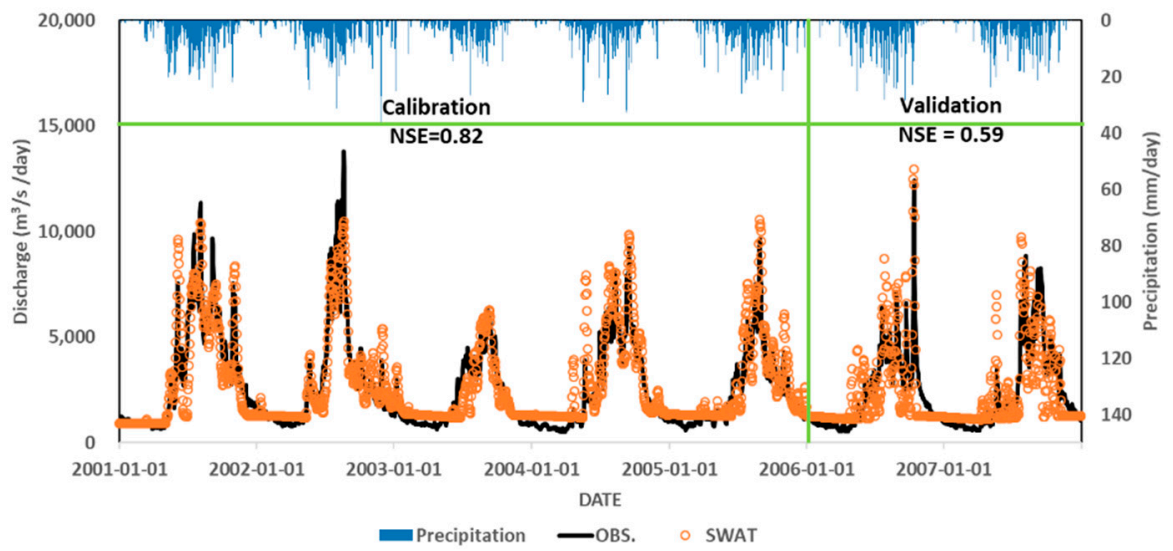

(a)

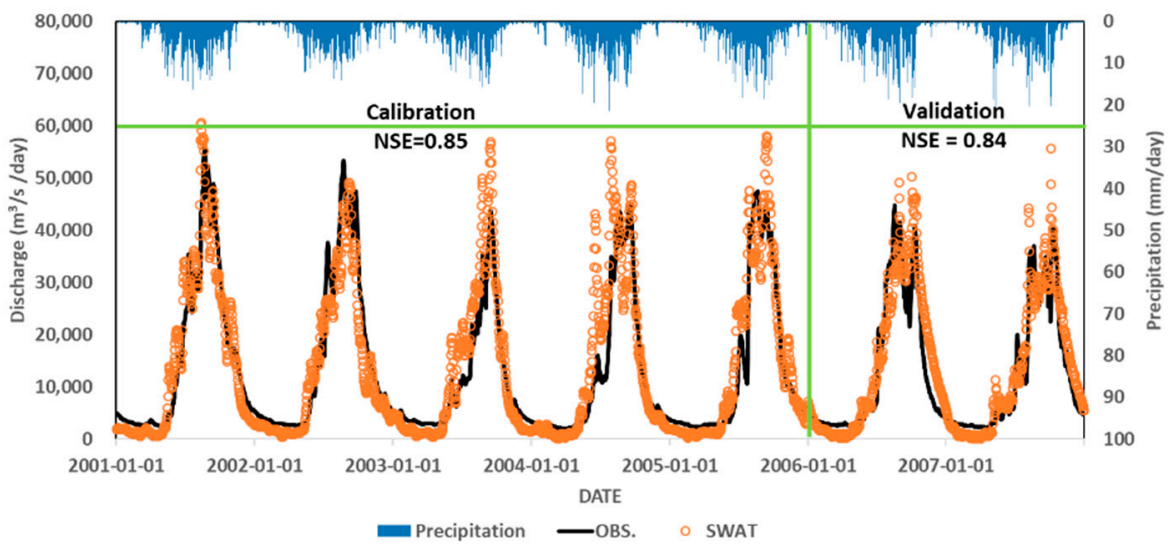

(b)

Figure 4. Comparison of hydrographs at the Chiang Saen and Kratie stations. (a) Chiang Saen; (b) Kratie.

The runoff analysis was conducted by applying the bias-corrected climate change scenario of the future period (2018-2100) using parameters that passed through the calibration and verification processes. Figure 5 shows the runoff analysis result of the future period by scenario in the Kratie station using the SWAT model. The seasonal M-K test was conducted to identify any trends. The mean, minimum, and maximum value and standard deviation of the annual runoff in the Kratie station in the RCP 4.5 scenario for the future period were around $12,819 \mathrm{~m}^{3} / \mathrm{s}, 8675 \mathrm{~m}^{3} / \mathrm{s}, 18,632 \mathrm{~m}^{3} / \mathrm{s}$, and $1919 \mathrm{~m}^{3} / \mathrm{s}$. The trend analysis yielded a Tau and p of 0.013 and 0.653 , which shows that the runoff increase is not a statistically significant trend. The mean, minimum, and maximum value and standard deviation of the annual runoff in the Kratie station in the RCP 8.5 scenario were approximately $13,394 \mathrm{~m}^{3} / \mathrm{s}$, $6893 \mathrm{~m}^{3} / \mathrm{s}, 20,066 \mathrm{~m}^{3} / \mathrm{s}$, and $2308 \mathrm{~m}^{3} / \mathrm{s}$. The trend analysis shows that Tau and pare -0.039 and 0.170 , which indicates that the runoff decrease is also not a statistically significant trend. 


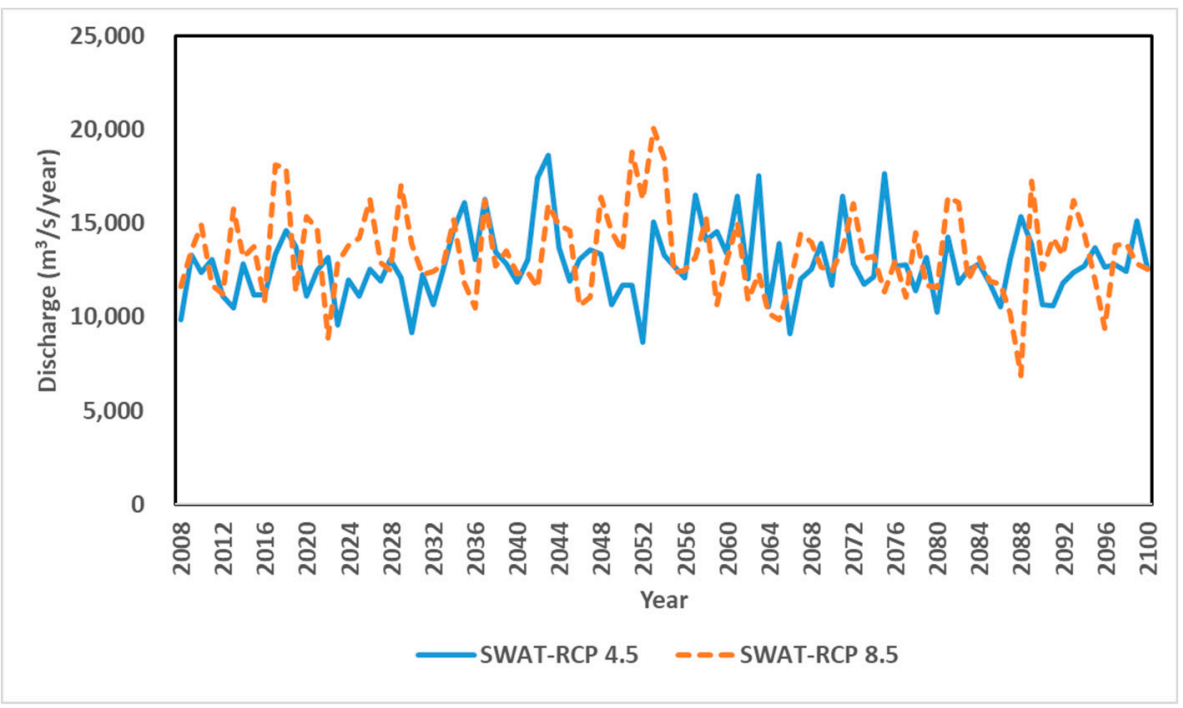

Figure 5. Yearly-average discharge trends in the RCP 4.5 and 8.5 scenarios (SWAT).

\subsection{LSTM Runoff Analysis Result}

The learning and verification in the LSTM model were conducted for the 1980-2007 period, in which the observation data of the Kratie water level observatory and APHRODITE rainfall data were acquired at the same time. Next, the future water level was predicted for each scenario by applying the bias-corrected area mean scenario rainfall in the 23 selected sub-basins in the RCP 4.5 and 8.5 scenarios for the future period between 2008 and 2100. Table 5 summarizes the reproducibility analysis for each case according to the change in sequence length for the verification period. The reproducibility of the water level prediction was 0.99 or higher in all cases, demonstrating that good learning was achieved. Out of seven cases, when the sequence length was 6 , the reproducibility was 0.997 , which was the highest. The reproducibility tended to decrease as the sequence length increased. This means that it was most efficient when the learning and prediction of the change in water level in the Kratie station using the LSTM model were performed using 6-day data. Figure 6 shows the prediction results for the LSTM verification period for a sequence length of 6.

Table 5. Model performance results of the LSTM model.

\begin{tabular}{ccc}
\hline Case & Sequence Length (days) & NSE \\
\hline 1 & 1 & 0.996 \\
2 & 3 & 0.996 \\
3 & 6 & 0.997 \\
4 & 9 & 0.996 \\
5 & 12 & 0.996 \\
6 & 15 & 0.996 \\
7 & 30 & 0.995 \\
\hline
\end{tabular}




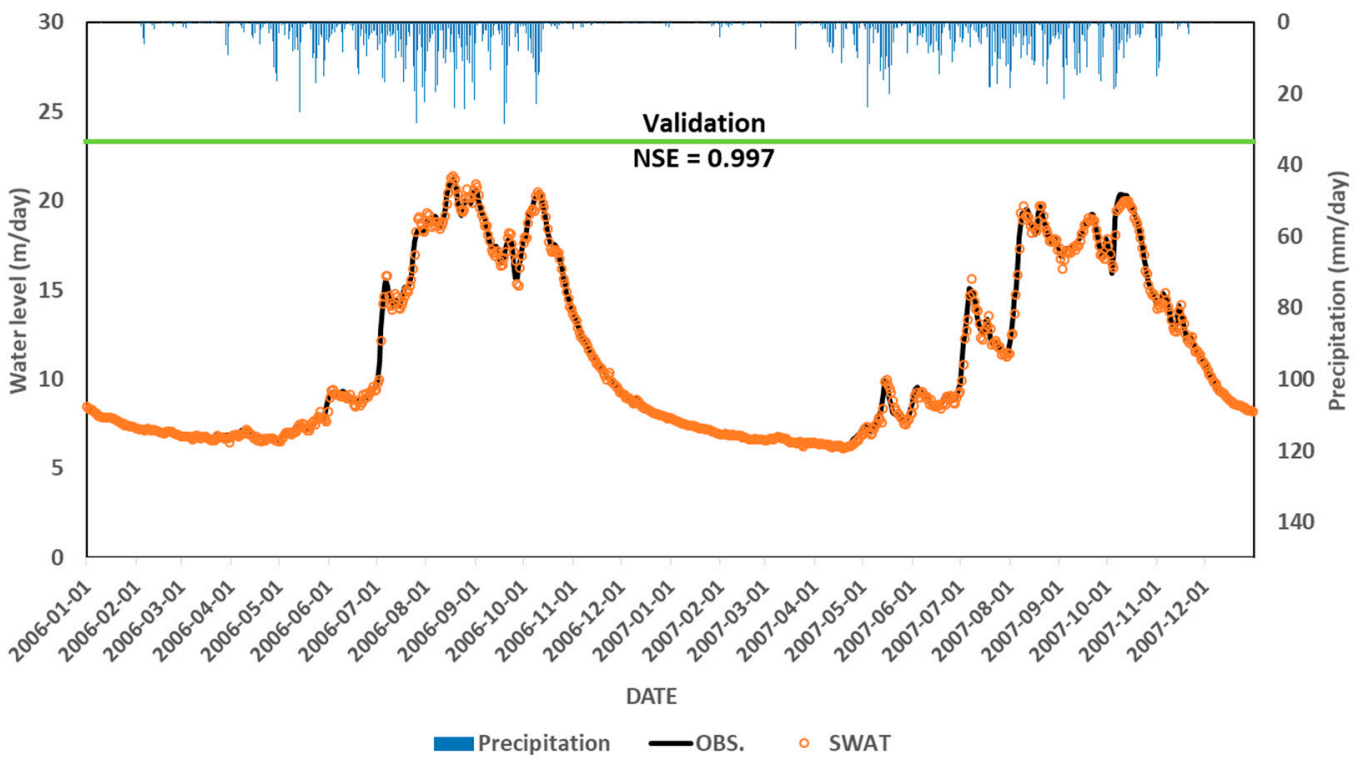

Figure 6. Comparison of water levels at the Kratie station (Case 6).

Figure 7 shows the change in runoff in the Kratie station for the future period using the climate change scenario by means of the LSTM model in the sequence length 6 condition. The future water level prediction results in the RCP 4.5 and 8.5 scenarios were converted into flow rates using the rating curve equation proposed by the MRC [38]:

$$
Q=(8.158 H)-10.255^{2.1}
$$

where $Q$ is the discharge $\left(\mathrm{m}^{3} / \mathrm{s}\right)$ and $H$ is the water level $(\mathrm{m})$.

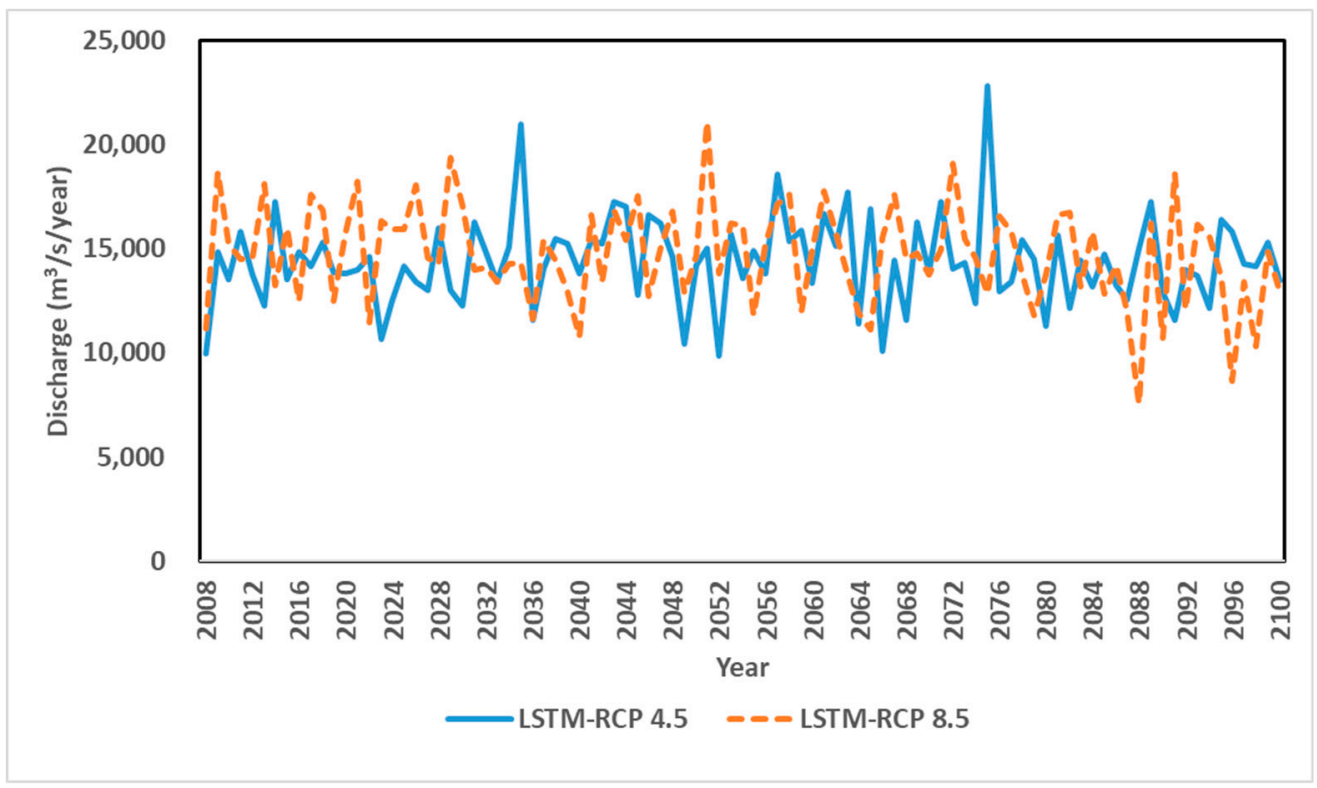

Figure 7. The yearly-average discharge trends in the RCP 4.5 and 8.5 scenarios (LSTM).

The seasonal M-K test was conducted to analyze the trends in future runoff using the LSTM model. The mean, minimum, and maximum value and standard deviation of the annual runoff in the Kratie station in the RCP 4.5 scenario for the future period were around $14,390 \mathrm{~m}^{3} / \mathrm{s}, 9867 \mathrm{~m}^{3} / \mathrm{s}, 22,844 \mathrm{~m}^{3} / \mathrm{s}$, and $2138 \mathrm{~m}^{3} / \mathrm{s}$. The trend analysis yielded a Tau and $\mathrm{p}$ of 0.022 and 0.399 , which indicates that the increase in runoff was not a statistically significant trend. On the other hand, the mean, minimum, 
and maximum value and standard deviation of the annual runoff in the Kratie station in the RCP 8.5 scenario were around 14,717 $\mathrm{m}^{3} / \mathrm{s}, 7595 \mathrm{~m}^{3} / \mathrm{s}, 21,123 \mathrm{~m}^{3} / \mathrm{s}$, and $2405 \mathrm{~m}^{3} / \mathrm{s}$. The trend analysis results for Tau and $\mathrm{p}$ were -0.033 and 0.233 , which suggest that the decrease in runoff is also not a statistically significant trend.

\subsection{Comparison of Future Runoff Results}

The investigation results of the runoff analysis for the future period exhibited that neither model yielded any statistically significant trend for either scenario, as shown in Figures 5 and 7 . However, when considering the value of Tau in the seasonal M-K test result in the RCP 4.5 scenario, the runoff analysis result using the SWAT model was 0.013 and using the LSTM model was 0.022 , numbers which indicate an increasing trend. In the RCP 8.5 scenario, the runoff analysis Tau obtained using the SWAT model was -0.039 and using the LSTM model was -0.033 , both of which reveal a decreasing trend. This is because the Tau values of Basins 9-23 in the downstream tended to decrease in the M-K test result of climate change scenario rainfall data by sub-basin (as seen in Table 3), and the decreasing trends in Basins 11 and 13 were statistically significant.

This result indicates that the future runoff prediction results of LSTM and SWAT show similar trends. However, according to the time-series data, the LSTM runoff simulation showed a higher reproducibility than that by SWAT. As previously mentioned, both the physical rainfall-runoff and SWAT models applied in this study include several sources of uncertainty that occurred during the determination or estimation process of parameters and various basic data. In particular, for regions whose basic data are difficult to acquire and the reliability of the acquired data is low, the accuracy of the runoff analysis results is unreliable. Thus, since the LSTM model can derive relatively accurate results using only a small amount of data, it can be very effective when only a runoff time-series is available, as is the case in this study.

\section{Conclusions and Discussion}

This study proposed a rainfall-runoff analysis system for the Kratie station, which is along the mainstream of the Mekong River, using the physical rainfall-runoff SWAT model and the data-based black-box LSTM model. Simulations of future runoff variations were performed by applying two climate change scenarios. Except for the observation flow rate and temperature data, the basic data required by the SWAT model were developed by using globally available data (topography: HydroSHED; land use: GLCF-MODIS; soil: FAO-Soil map; and rainfall: APHRODITE). The optimal parameters were derived and the model was verified for the period of 2000-2007, which includes one year for the model stabilization period (warm-up period). In the LSTM model, the water level data of the Kratie station and observation rainfalls in 23 upstream basins were trained for the 1980-2005 period, and the training results were verified for the 2006-2007 period. The runoff analysis was subsequently performed for the 2008-2100 interval using both models by applying the bias-corrected RCP 4.5 and 8.5 climate change scenarios (SWAT: rainfalls and maximum and minimum temperatures; LSTM: rainfalls).

The evaluation results of the reproducibility at the Kratie station for the verification period (2006-2007) of the two models developed in this study showed that the SWAT model's NSE was 0.84, while the LSTM's NSE was 0.99, indicating excellent results from both models. However, the LSTM model showed a higher reproducibility and provided more stable runoff simulation results than the SWAT model regardless of the flow rates being high or low, conditions in which the SWAT accuracy was irregular.

The future runoff predictions for the Kratie station using the SWAT model for the 2008-2100 period yielded the following mean, minimum, maximum, and standard deviations of the annual runoff: $12,819 \mathrm{~m}^{3} / \mathrm{s}, 8675 \mathrm{~m}^{3} / \mathrm{s}, 18,632 \mathrm{~m}^{3} / \mathrm{s}$, and $1919 \mathrm{~m}^{3} / \mathrm{s}$, respectively, under the RCP 4.5 scenario and approximately $13,394 \mathrm{~m}^{3} / \mathrm{s}, 6893 \mathrm{~m}^{3} / \mathrm{s}, 20,066 \mathrm{~m}^{3} / \mathrm{s}$, and $2308 \mathrm{~m}^{3} / \mathrm{s}$, respectively, under the RCP 8.5 scenario. In the LSTM model, the mean, minimum, maximum, and standard deviation of the annual runoff were approximately $14,390 \mathrm{~m}^{3} / \mathrm{s}, 9867 \mathrm{~m}^{3} / \mathrm{s}, 22,844 \mathrm{~m}^{3} / \mathrm{s}$, and $2138 \mathrm{~m}^{3} / \mathrm{s}$, respectively, under the 
RCP 4.5 scenario, and approximately $14,717 \mathrm{~m}^{3} / \mathrm{s}, 7595 \mathrm{~m}^{3} / \mathrm{s}, 21,123 \mathrm{~m}^{3} / \mathrm{s}$, and $2405 \mathrm{~m}^{3} / \mathrm{s}$, respectively, under the RCP 8.5 scenario. It is notable that the RCP 8.5 scenario had a larger variety of annual flow rates than the RCP 4.5 scenario in both of the models. The trend analysis results of the seasonal M-K test revealed that neither model found a statistically significant trend by scenario. However, when considering only the Tau value in the RCP 4.5 scenario, which was 0.013 in the SWAT and 0.022 in the LSTM model, an increasing trend could be identified. In the RCP 8.5 scenario, the runoff analysis results yielded a Tau of -0.039 for the SWAT model and -0.033 for the LSTM model, both approaches indicating a decreasing trend.

The climate change scenario contains very high uncertainty levels compared to the actual climate change process due to the selection of virtual future scenarios, incomplete physical understanding of various natural conditions, and the limitation in computational capabilities; in addition, the runoff analysis using these scenarios will also be accompanied by additional errors and uncertainties. In particular, when performing a runoff analysis for regions whose reliability of observation data is low, as is the case in this study, by applying a physical rainfall-runoff model, a number of uncertainties are incorporated during the determination and estimation of parameters and various basic data. Thus, the LSTM model, which can derive relatively accurate results using only a small amount of data, can be very effective when only a runoff time series is available. However, a data-based hydrological model, such as LSTM, can only consider a simulation of changes in simple runoff time series excluding the effects by land-use change in basins or development of river structures. Another limitation of the rainfall-runoff model is that it only considers the simulated changes in runoff time series is considered, the information about dam discharge in the Mekong River basin remaining undisclosed. Offering access to such data in the future will be highly important for reliable simulations of changes in runoff in the Mekong River basin.

Author Contributions: D.L. and G.L. designed the analytical framework of this study. D.L. and S.J. performed the data analysis. D.L. drafted the manuscript. S.K. provided methodological advice. All authors have read and agreed to the published version of the manuscript.

Funding: This work was supported by Korea Environment Industry \& Technology Institute (KEITI) through Water Management Research Program, funded by Korea Ministry of Environment (MOE) (127562).

Conflicts of Interest: The authors declare no conflict of interest.

\section{References}

1. Kim, J.H. Transboundary water issue: The case of hydropower in the Mekong river basin. Mag. Korea Water Resour. Assoc. Water Future 2013, 46, 28-33.

2. Lee, G.H.; Jung, S.H.; Lee, D.E. Comparison of physics-based and data-driven models for streamflow simulation of the Mekong River. J. Korea Water Resour. Assoc. 2018, 51, 503-514. [CrossRef]

3. Pasgaard, M.; Strange, N. A quantitative analysis of the causes of the global climate change research distribution. Glob. Environ. Chang. 2013, 23, 1684-1693. [CrossRef]

4. Korea Institute of Science and Technology Information. Global Trends Briefing; Korea Institute of Science and Technology Information: Seoul, Korea, 2014.

5. World Bank. World Development Report: Development and Climate Change; World Bank: Washington, DC, USA, 2010.

6. $\quad$ Eastham, J.; Mpelasoka, F.; Mainuddin, M.; Ticehurst, C.; Dyce, P.; Hodgson, G.; Ali, R.; Kirby, M. Mekong River Basin Water Resources Assessment: Impacts of Climate Change; CSIRO: Canberra, Australia, 2008.

7. Hoanh, C.T.; Jirayoot, K.; Lacombe, G.; Srinetr, V. Comparison of Climate Change Impacts and Development Effects on Future Mekong Flow Regime. In Proceedings of the International Congress on Environmental Modelling and Software Modelling for Environment's Sake, Fifth Biennial Meeting, Ottawa, ON, Canada, 5-8 July 2010.

8. Kingston, D.G.; Thompson, J.R.; Kite, G. Uncertainty in climate change projections of discharge for the Mekong River Basin. Hydrol. Earth Syst. Sci. 2011, 15, 1459-1471. [CrossRef] 
9. Lauri, H.; Moel, H.D.; Ward, P.J.; Räsänen, T.A.; Keskinen, M.; Kummu, M.S. Future changes in Mekong River hydrology: Impact of climate change and reservoir operation on discharge. Hydrol. Earth Syst. Sci. 2012, 16, 4603-4619. [CrossRef]

10. Hoang, P.L.; Lauri, H.; Kummu, M.; Koponen, J.; Van Vliet, M.T.; Supit, I.; Leemans, R.; Kabat, P.; Ludwig, F. Mekong River flow and hydrological extremes under climate change. Hydrol. Earth Syst. Sci. Discuss. 2016, 20, 3027-3041. [CrossRef]

11. Tran, Q.K.; Song, S.K. Water level forecasting based on deep learning: A use case of Rinity River-Texas-the United States. J. KIISE 2017, 44, 607-612. [CrossRef]

12. Jung, S.H.; Lee, D.E.; Lee, K.S. Prediction of river water level using deep-learning open library. J. Korean Soc. Hazard Mitig. 2018, 18,1-11. [CrossRef]

13. Hochreiter, S.; Schmidhuber, J. Long short-term memory. Neural Comput. 1997, 9, 1735-1780. [CrossRef]

14. Joh, H.K.; Park, J.Y.; Jang, C.H.; Kim, S.J. Comparing prediction uncertainty analysis techniques of SWAT simulated stream flow applied to Chungju dam watershed. J. Korea Water Resour. Assoc. 2012, 45, 861-874. [CrossRef]

15. Yang, J.; Reichert, P.; Abbaspour, K.C.; Xia, J.; Yang, H. Comparing uncertainty analysis techniques for a SWAT application to the Chaohe Basin in China. J. Hydrol. 2008, 358, 1-23. [CrossRef]

16. Setegn, S.G.; Srinivasan, R.; Melesse, A.M.; Dargahi, B. SWAT model application and prediction uncertainty analysis in the Lake Tana basin, Ethiopia. Hydrol. Process. 2010, 24, 357-367. [CrossRef]

17. Shrestha, B.; Babel, M.S.; Maskey, S.; Griensven, A.V.; Uhlenbrook, S.; Green, A.; Akkharath, I. Impact of climate change on sediment yield in the Mekong River basin: A case study of the Nam Ou basin, Lao PDR. Hydrol. Earth Syst. Sci. 2013, 17, 1-20. [CrossRef]

18. Olah, C. Understanding Lstm Networks. GITHUB. Available online: http://colah.github.io/posts/2015-08Understanding-LSTMs/ (accessed on 20 March 2020).

19. Ka, S.H.; Lee, J.E.; Oh, J.J. Status and strategy for the climate observation science in Korea. J. Korean Soc. Environ. Anal. 2013, 16, 42-48.

20. KMA. Case Studies to Understand and Take Advantage of Climate Change Scenarios; Korea Meteorological Administration: Seoul, Korea, 2012.

21. Giorgi, F.; Francisco, R. Evaluating uncertainties in the prediction of regional climate change. Geophys. Res. Lett. 2000, 27, 1295. [CrossRef]

22. Mark, N.; Mike, H. Representing uncertainty in climate change scenarios: A monte-carlo approach. Integr. Assess. 2000, 1, 203-213. [CrossRef]

23. Aggarwal, P.K.; Mall, R.K. Climate change and rice yields in diverse agro-environments of India. II. Effect of uncertainties in scenarios and crop models on impact assessment. Clim. Chang. 2002, 52, 331-343. [CrossRef]

24. Muerth, M.J.; Gauvin St-Denis, B.; Ricard, S.; Velázquez, J.A.; Schmid, J.; Minville, M.; Caya, D.; Chaumont, D.; Ludwig, R.; Turcotte, R. On the need for bias correction in regional climate scenarios to assess climate change impacts on river runoff. Hydrol. Earth Syst. Sci. 2013, 17, 1189-1204. [CrossRef]

25. Kum, D.; Park, Y.; Jung, Y.H.; Shin, M.H.; Ryu, J.; Park, J.H.; Yang, J.E.; Lim, K.J. Analysis of rainfall-runoff characteristics on bias correction method of climate change scenarios. J. Korean Soc. Water Environ. 2015, 31, 241-252. [CrossRef]

26. Hewitson, B.C.; Crane, R.G. Consensus between GCM climate change projections with empirical downscaling: Precipitation downscaling over South Africa. Int. J. Climatol. 2006, 26, 1315-1337. [CrossRef]

27. Fowler, H.J.; Blenkinsop, S.; Tebaldi, C. Linking climate change modeling to impacts studies: Recent advances in downscaling techniques for hydrological modelling. Int. J. Climatol. 2007, 27, 1547-1578. [CrossRef]

28. Ning, L.; Mann, M.E.; Crane, R.; Wagener, T.; Najjar, R.G.; Singh, R. Probabilistic projections of anthropogenic climate change impacts on precipitation for the mid-Atlantic region of the United States. J. Clim. 2012, 25, 5273-5291. [CrossRef]

29. Bürger, G.; Murdock, T.Q.; Werner, A.T.; Sobie, S.R. Downscaling extremes-an intercomparison of multiple statistical methods for present climate. J. Clim. 2012, 25, 4366-4388. [CrossRef]

30. MRC. Mekong River Commission for Sustainable Development: About the Mekong, Water at Work; Mekong River Commission: Vientiane, Laos, 2009.

31. Việt, T. The Lower Mekong Dams Factsheet Text; International Rivers: Oakland, CA, USA; Available online: https://www.internationalrivers.org/resources/the-lower-mekong-dams-factsheet-text-7908 (accessed on 20 March 2020). 
32. Wang, W.; Lu, H.; Yang, D.; Sothea, K.; Jiao, Y.; Gao, B.; Peng, X.; Pang, Z. Modelling hydrologic processes in the Mekong River basin using a distributed model driven by satellite precipitation and rain gauge observations. PLOS ONE 2016, 11. [CrossRef]

33. Lee, D.E.; Yu, W.S.; Lee, G.H. Large scale rainfall-runoff analysis using SWAT model: Case study: Mekong River basin. J. Korean Soc. Agric. Eng. 2018, 60, 47-57. [CrossRef]

34. Mann, H. Nonparametric tests against trend. Econometrica 1945, 13, 245-259. [CrossRef]

35. Kendall, M. Rank Correlation Methods; Charles Griffin: London, UK, 1975.

36. Oh, J.S.; Kim, B.S.; Kim, H.S.; Seo, B.H. Trend detection of serially correlated hydrologic series. J. Korean Wetl. Soc. 2004, 1, 1229-6031.

37. Yun, J.; Hwang, S.; Kim, D.; Kim, S. Trend analysis of monthly water quality data in Nakdong River based on seasonal Mann-Kendall test. J. Korean Soc. Agric. Eng. 2015, 57, 153-162. [CrossRef]

38. Mekong River Commission. The Study on Hydro-Meteorological Monitoring for Water Quantity Rules in Mekong River Basin; Mekong River Commission: Vientiane, Laos, 2004.

(C) 2020 by the authors. Licensee MDPI, Basel, Switzerland. This article is an open access article distributed under the terms and conditions of the Creative Commons Attribution (CC BY) license (http://creativecommons.org/licenses/by/4.0/). 